Research Paper:

\title{
Effects of Health Belief Model-based Education on Maternal Abilities to Caring for Children With Avoidant Restrictive Food Intake Disorder
}

\author{
Yoyok Bekti Prasetyo $^{1^{*}}$ (D), Yulis Setiya Dewi ${ }^{2}$ (D)
}

1. Department of Community Nursing, Faculty of Health Sciences, Muhammadiyah University of Magelang, Malang, Indonesia.

2. Department of Emergency Nursing, Faculty of Nursing, Airlangga University, Surabaya, Indonesia.

\begin{tabular}{c|l}
$\begin{array}{c}\text { Use your device to scan } \\
\text { and read the aticle online }\end{array}$ \\
ing for Children With Avoidant Restrictive Food Intake Disorder. Journal of Client-Centered Nursing Care, 7(3), pp. 205-214. \\
https://doi.org/10.32598/JCCNC.7.3.376.1
\end{tabular}

\section{(c) (1) (3)}

Article info:

Received: 03 Jun 2021

Accepted: 04 Jul 2021

Published: 01 Aug 2021

Keywords:

Health education, Health belief model, Food intake regulation, Childhood eating and feeding disorders, Maternal behavior

\section{A B S T RA C T}

Background: Health education, using new approaches in the nursing area, is of great importance. The current study aimed to evaluate the effects of a health belief model-based education on maternal abilities to caring for children with Avoidant Restrictive Food Intake Disorder (ARFID).

Methods: This was a quasi-experimental non-randomized controlled trial with pre-test, post-test and a control group design. In total, 30 families with children with ARFID in Malang regency, Indonesia were divided into experimental $(n=15)$ and control $(n=15)$ groups. The experimental group was trained based on the Health Belief Model (HBM); however, the control group received an education based on the routine nursing process model. The necessary data were collected by a researcher-made questionnaire constructed based on HBM constructs. The obtained data were analyzed in SPSS. Descriptive statistics, homogeneity test, and Paired-Samples t-test were used to outline the relationship between the dependent and independent variables.

Results: HBM effectively improved maternal abilities to manage eating disorders $(\mathrm{P}=0.009)$, promoting behaviors $(\mathrm{P}=0.000)$, and paternal involvement $(\mathrm{P}=0.000)$.

Conclusion: HBM-Based education is recommended to be used in the provision of training in the mothers of children with ARFID.

\section{* Corresponding Author:}




\section{Highlights}

- The mean score of motherhood abilities in the experimental group was significantly higher than that of the control group.

- Health Belief Model-Based education improved the explored mothers' abilities to manage the eating disorders of their children.

- Health Belief Model-Based education improved the promoting behaviors of the mothers of children with ARFID.

- Health Belief Model-Based education improved the examined mothers' abilities in the involvement of fathers in caring for their children with ARFID.

\section{Plain Language Summary}

Health promotion and preventive behaviors are the most basic strategies in improving maternal abilities to manage eating disorders, promoting behavior, and paternal involvement. The present study results indicated that health belief model-based education improves maternal abilities to take care of their children with ARFID according to the criteria of managing eating disorders, promoting behaviors, and paternal involvement.

\section{Introduction}

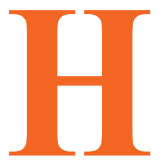

ealth education programs play an essential role in improving the nursing profession. It is a manifestation of nursing intervention that influences affective, cognitive, and behavioral characteristics (Lee et al. 2018). Health education using new approaches in the nursing area is of great importance (Sanaie et al. 2019). It is mainly because traditional health education is less effective in improving individual motivation, knowledge, and skill (Policicchio et al. 2019). Mothers' belief in health issues and preventive behaviors essentially impact promoting or interfering with health behaviors (Didarloo, Nabilou \& Khalkhali 2017). A weak belief may contribute to failure to get medical help due to the lack of perceived control upon health matters that happen (Reiff et al. 2017). Health Belief Model (HBM) could be used as a guide to improving healthy behaviors. Teaching according to HBM is based on the theory of HBM. Generally, the HBM is used to determine whether an individual has committed precautionary actions on health issues and health promotion activities (Akey, Rintamaki \& Kane 2013); explain why they change or keep practicing specific health activities (James et al.2012, Poortaghi et al. 2015); describe why individuals fail to participate in any activities aiming for detection or prevention from particular illnesses (Borowski \& Tambling 2015); predict what they should do for preventive actions; conduct screening tests, and control the illness (Glanz, Rimer \& Viswanath 2008). HBM-Based education further refers to a health education program conducted by health professionals to assist individuals to take measures for prediction, taking action, and promoting behavioral change over healthy and ill conditions.

Avoidant Restrictive Food Intake Disorder (ARFID) is a new term for a feeding disorder that affects infants and toddlers. It includes rejection to eat, irregular eating patterns, and a failure to demonstrate eating skills adequate for their developmental stage. The extent of promotional and preventive behaviors in the management of ARFID cases remains to be less than necessary. The majority of mothers taking care of children with ARFID appear to encounter extensive stress from overpressure and distress due to their children's eating disorders (Mairs \& Nicholls 2016). The prevalence of stressful parent-children bonding falls in the range of $13 \%-82 \%$, depending on the risk factors in the family, such as negligence and maltreatment on the children (Skovgaard Væver, Smith-Nielsen \& Lange 2016).

Health promotion and preventive behaviors are the most basic strategies in improving motherhood's ability to manage eating disorders, promoting behavior, and paternal involvement. Health promotion is not only intended to reinforce individual skills and abilities but also to evenly distribute health services and properly fulfill human rights (Maijala, Tossavainen \& Turunen 2016). Nurses are responsible for reducing the frequency of unhealthy behaviors through health education programs (Arslan Yurumezoglu \& Gokce Isbir 2019; Younas et al. 2019). Additionally, evaluating health education programs is es- 
sential for identifying success and satisfaction among patients (Malekzadeh, Amouzeshi \& Mazlom 2018).

Nurses frequently fail to conduct health education programs for behavior change among the patients. Two main reasons explain why health education programs cannot run very well. First, the nurses are unwilling to attempt to promote a healthy lifestyle, especially if they have no such experience. Secondly, any suggestions from the nurses might sound credible; however, the patients are unwilling to follow those (Kelly, Wills \& Sykes 2017). Less credible education is related to nurses' low understanding of particular cases the patients undergo. Mothers who take care of children with ARFID experience role strain. A familial environment may influence the occurrence of strain or stress amongst mothers, which in turn, will rise behavioral problems, like problematic parent-child interaction (Yoo, Popp \& Robinson 2014). Furthermore, a supportive home environment, including a parenting system and proximity amongst family members, present positive effects on children's appropriate eating skills (Melbye et al. 2013).

HBM, as a model of behavioral changes in individuals, has been widely used to predict one's health behaviors (Ashoori et al. 2020), developed through fear and risk management (Tajeri Moghadam et al. 2020), and used for protective actions, such as screening and examination (Yuen et al. 2020). Furthermore, the basic concepts of HBM encompass 5 factors, namely perceived susceptibility, perceived severity, perceived benefit, perceived barrier, and self-efficacy (Ma 2018; Gabriel, Hoch \& Cramer, 2019; Lee et al. 2019; Ashoori et al. 2020). HBM-Based education could be used to rise mothers' belief in taking care of their children with ARFID. Additionally, the HBM concept has become very essential in solving the parenting problems, especially in the families that raise children with ARFID, due to several reasons, such as the following: When children have more serious problems due to delays in proper treatment, mothers experience further anxiety, and mothers feel helpless in the treatment process due to the child's condition not changing and losing confidence. Any activities related to proper and healthy food selection are strongly dependent on belief matters, i.e., self-efficacy, perceived benefit, and perceived barrier. Ideally speaking, self-efficacy improves perceived benefits and reduces perceived barriers to healthy eating behavior (Kamimura et al. 2016).

Health education programs for mothers are related to the mother's educational background. It is stated that mothers' education background influences children's nutritional status (Hossain, 2020). In other words, the higher the mother's educational background, the better the quality of children's health (Karki Nepal 2018). Thus, it is necessary to research by highlighting how maternal belief contributes to the best decision-making in taking care of children with nutritional disorders, like ARFID. Accordingly, the current study is deemed very crucial to carry out in the attempt of examining the success of HBM-based training for mothers for taking care of children with ARFID. Accordingly, the present study aimed to determine the effects of HBM-based education on maternal abilities to care for children with ARFID.

\section{Materials and Methods}

This was a quasi-experimental non-randomized controlled trial with pre-test, post-test and a control group design.

All mothers of children with ARFID in Malang Regency, Indonesia included the research population. To determine the sample size, the Z-value on the normal curve in one-way hypothesis testing signified 1.64 in the significance level of $\alpha=0.05$. Moreover, at the significance level of $\alpha=0.02$, the $Z$-value on the normal curve equaled 1.285. Besides, with 0.65 Standard Deviation (SD) of the research population, the sample size constituted 15 mothers per group. Additionally, the inclusion criteria included the mothers of children with ARFID and consent to participate in the study. The subjects who did not attend the sessions were excluded from the study.

The study was conducted from January to March 2019. The researchers queried an informed consent to the respondents by explaining to them the goals and benefits of the research along with the research procedures. After the pre-test, the experimental group was trained based on HBM constructs for 3 weeks with 3 sessions in total. In each session, the effective time of training lasted for 50-60 minutes. Furthermore, in every single session, the materials were delivered using the visual media of power-point slides and the projector screen. The content of the sessions concerned the father's involvement (the first session), managing eating disorder (the second session), and promotional behavior (the third session). Differently, the health education program was delivered for the control group through a home visits and hand in a module. In the control group, the intervention was applied same as the experimental group, but in two sessions based on the routine nursing process model. A post-test was conducted on both study groups. The flow diagram of the study process is illustrated in (Figure 1). The required data were collected by a researcher-made questionnaire based on HBM constructs. It has 4 basic parts, including demographic data (age, educational background, the 


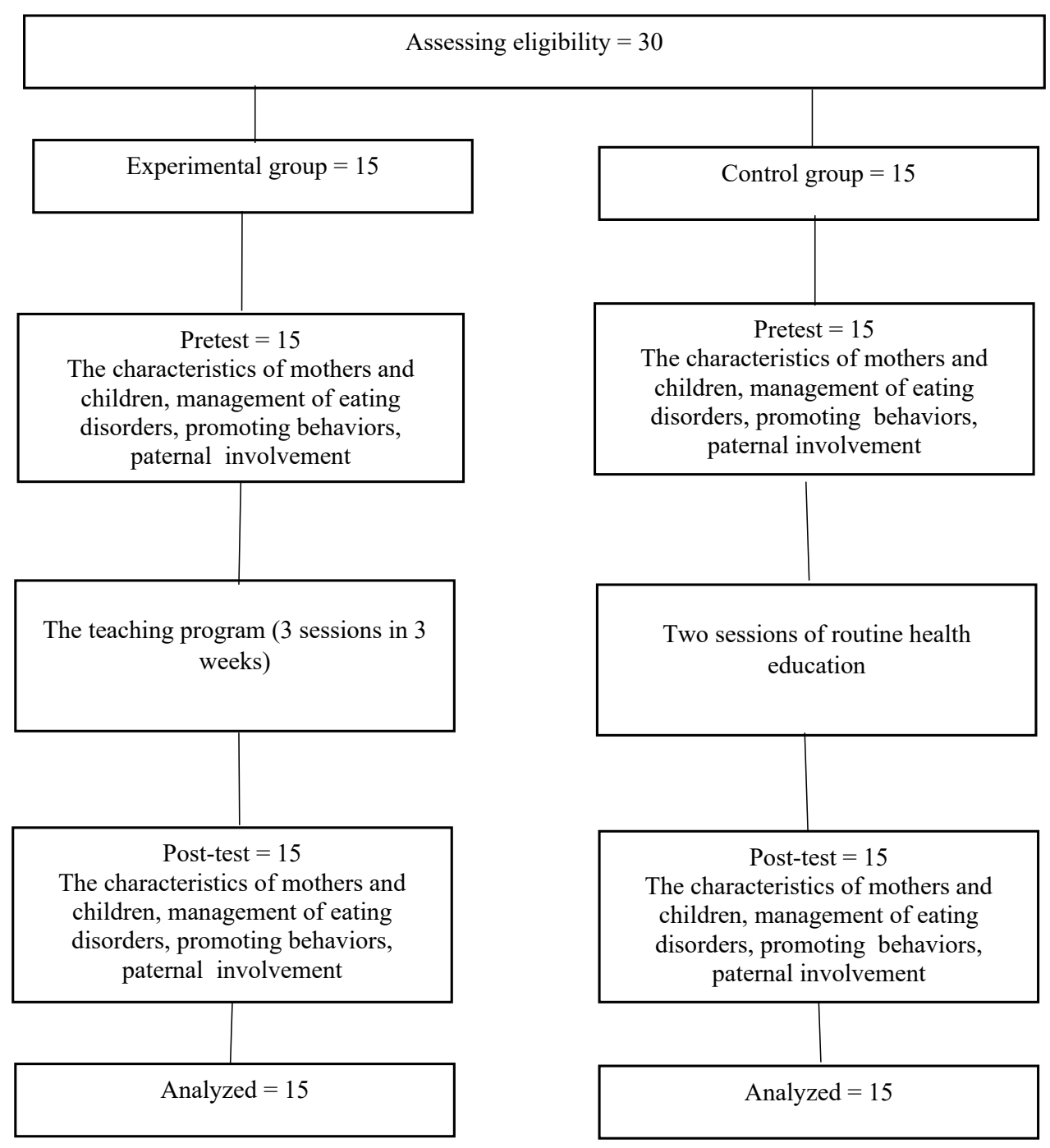

Figure 1. The flow diagram of the study process

number of children, \& income), the management of eating disorders, the management of promoting behaviors, and paternal involvement.

Specifically, the questionnaire related to the management of eating disorders composed 9 statements in total based on the following indicators: collaboration with medical personnel, cooperativeness with family members, the reinforcement of positive relationship, monitoring vital signs, monitoring fluid intake and output, satisfactory fulfillment of expectations, using behavioral modifications, discussion with the health teams, and taking over responsibility. Besides, a 5-point Likert-type scale was also used (1=never, $2=$ seldom, $3=$ sometimes, 4=frequently, and 5= always). The cut-off points was detected using the median value. Scores ranged from 9 to 45, and higher scores indicate better management of eating disorders.
The questionnaire for promoting behaviors was composed of 11 statements on the following indicators: proposing proper questions, accomplishing tasks, showing early examination, getting in contact with medical personnel, demonstrating skills, explaining strategy for behavioral changes, obeying the strategy, practicing healthy behaviors, seeking for health information, elaborating a strategy to maximize health, and develop a strategy for individual development. Furthermore, a 5-point Likert-type scale was used with the descriptors of $1=$ never, $2=$ seldom, $3=$ sometimes, $4=$ frequently, and $5=$ always. The cut-off points was detected using the median value. The obtainable scores range from 11 to 55 , and higher scores indicate better-promoting behaviors.

The questionnaire for paternal involvement included 7 statements on the following indicators: paternal involvement in making out parenting atmosphere, fathers' 
Table 1. Demographical characteristics of the research groups

\begin{tabular}{|c|c|c|c|}
\hline \multirow{2}{*}{\multicolumn{2}{|c|}{ Characteristics }} & \multicolumn{2}{|c|}{ No.(\%) } \\
\hline & & Experimental $(n=15)$ & Control $(n=15)$ \\
\hline \multicolumn{2}{|c|}{ Mothers' ages (Mean/range) } & $31.6 / 23-39$ & $30.8 / 21-41$ \\
\hline \multirow{3}{*}{ Educational background } & Elementary school & - & $3(20)$ \\
\hline & Junior high school & $1(6.7)$ & $8(53.3)$ \\
\hline & Senior high school & 14(93.3) & $4(26.7)$ \\
\hline \multirow{2}{*}{ Occupations } & Employed & $2(13.3)$ & $4(26.7)$ \\
\hline & Unemployed & $13(86.7)$ & $11(73.3)$ \\
\hline \multirow{3}{*}{ Number of children } & 1 child & $8(53.3)$ & $9(60)$ \\
\hline & 2 children & $5(33.3)$ & $3(20)$ \\
\hline & 3 children & $2(13.3)$ & $3(20)$ \\
\hline \multirow{3}{*}{ Income/month } & $<1$ million & $3(20)$ & $2(13.3)$ \\
\hline & 1-2 million & $6(40)$ & $12(80)$ \\
\hline & $>2$ million & $6(40)$ & $1(6.7)$ \\
\hline \multirow{2}{*}{ Gender } & Male & $9(60)$ & $8(53.3)$ \\
\hline & Female & $6(40)$ & $7(46.7)$ \\
\hline \multicolumn{2}{|c|}{ Children's ages (mean/range) } & $2.3 / 1-4$ & $2.6 / 0.7-5$ \\
\hline
\end{tabular}

*Test of Homogeneity of Variances (Levene's test); $P=0.105$.

Client- Centered Nursing Care

support for children's success, paternal involvement in the parenting initiation, fathers' willingness in learning about children's success, fathers' influence on parenting, suggestion for fathers to always get involved at parenting, and fathers' unobligated task in seeking for parenting information. Additionally, a 5-point Likert-type scale was used with the descriptors of $1=$ never, $2=$ sel- dom, 3=sometimes, 4=frequently, and 5=always. Cutoff points were detected using the median value. Scores range from 7 to 35 , and higher scores indicate better-promoting behaviors. To ensure the validity of the questionnaire, it was reviewed by the related experts. Test-Retest results for managing eating disorders, promoting behaviors, and paternal involvement were as follows: $\mathrm{r}=0.89$,

Table 2. Comparing the mean scores of maternal abilities to manage eating disorders, promoting behaviors, and paternal involvement in the experimental and control groups

\begin{tabular}{|c|c|c|c|}
\hline \multirow{2}{*}{ Domains } & \multicolumn{2}{|c|}{ Mean $\pm S D$} & \multirow{2}{*}{$\mathbf{P}$} \\
\hline & $\begin{array}{c}\text { Experimental } \\
(n=15)\end{array}$ & $\begin{array}{c}\text { Control } \\
(n=15)\end{array}$ & \\
\hline Managing eating disorders & $4.8 \pm 0.6$ & $3.8 \pm 0.8$ & 0.001 \\
\hline Promoting behaviors & $6.5 \pm 0.5$ & $5.4 \pm 0.7$ & 0.000 \\
\hline Paternal involvement & $7.6 \pm 0.6$ & $4.9 \pm 0.8$ & 0.000 \\
\hline Total & $6.3 \pm 0.4$ & $4.8 \pm 0.5$ & 0.000 \\
\hline
\end{tabular}

Client- Centered Nursing Care 
Table 3. The paired samples t-test data for comparing the experimental and control groups

\begin{tabular}{|c|c|c|c|c|c|c|c|c|}
\hline & \multirow{3}{*}{ Groups } & \multicolumn{7}{|c|}{ Paired Differences } \\
\hline & & \multirow[t]{2}{*}{ Mean士SD } & \multirow{2}{*}{$\begin{array}{l}\text { Std } \\
\text { Error } \\
\text { Mean }\end{array}$} & \multicolumn{2}{|c|}{$\begin{array}{c}95 \% \text { Confidence } \\
\text { Interval of Difference }\end{array}$} & \multirow[t]{2}{*}{$\mathbf{t}$} & \multirow[t]{2}{*}{ df } & \multirow[t]{2}{*}{ P (2-tailed) } \\
\hline & & & & Lower & Upper & & & \\
\hline \multirow{3}{*}{ Experimental } & $\begin{array}{l}\text { Managing eating } \\
\text { disorders }\end{array}$ & $-0.533 \pm 0.990$ & 0.256 & -1.082 & 0.015 & -2.086 & 14 & 0.050 \\
\hline & Promoting behaviors & $-0.400 \pm 0.507$ & 0.131 & -0.681 & -0.119 & -3.055 & 14 & 0.009 \\
\hline & Paternal involvement & $-1.000 \pm 1.558$ & 0.402 & -1.863 & -0.137 & -2.485 & 14 & 0.026 \\
\hline \multirow{3}{*}{ Control } & $\begin{array}{l}\text { Managing eating } \\
\text { disorders }\end{array}$ & $-0.467 \pm 1.356$ & 0.350 & -1.217 & 0.284 & -1.333 & 14 & 0.204 \\
\hline & Promoting behaviors & $-0.067 \pm 0.594$ & 0.153 & -0.395 & 0.262 & -0.435 & 14 & 0.670 \\
\hline & Paternal involvement & $-0.200 \pm 1.146$ & 0.296 & -0.835 & 0.435 & -0.676 & 14 & 0.510 \\
\hline
\end{tabular}

$\mathrm{r}=0.83$, and $\mathrm{r}=0.80$, respectively. The internal consistency of the questionnaire was ensured by the Cronbach alpha coefficient, i.e., 0.89 for managing eating disorders, $(0.83)$ for promoting behaviors, and $(0.80)$ for paternal involvement.

Data analysis was conducted in SPSS. Descriptive statistics, homogeneity test, and Paired-Samples t-test were used to manifest the relationship between the dependent variables (managing eating disorders, promoting behaviors, \& paternal involvement) and the independent variable (HBM-based education). The significance level of the tests was set at 0.05 .

\section{Results}

The age range of the research subjects ranged from 41 to 21 years. Table 1 indicates that the average age of the mothers in the experimental and control groups were 31.6 and 30.8 years, respectively. The education and income level of the experimental group were higher than those of the control group. However, the differences in the demographic characteristics were already corrected using the homogeneity test $(\mathrm{P}=0.105>0.05)$, suggesting that both study groups were homogeneous or equivalent (Table 1).

The mean scores of maternal abilities to take care of children with ARFID concerning the 3 domains in the experimental and control groups indicated that the experimental group scores were better than those of the controls (Table 2).

Table 3 lists the results of the Paired-Samples t-test in the research groups. Accordingly, the maternal abilities in managing eating disorders, promoting behaviors, and paternal involvement have improved after receiving the intervention.

\section{Discussion}

The current study results indicated that the HBM-based education improved maternal abilities to take care of children with ARFID according to the criteria of managing eating disorders, promoting behaviors, and paternal involvement. Furthermore, the ability to manage eating disorders of the children was suggested by the collaboration of mothers with medical personnel, cooperation among family members, behavioral modifications, and a better sense of liability. This finding is in line with those of McCloskey et al.(1996) and Johnson and Moorhead (2000); they argued that health maintenance refers to any activities of identifying, controlling, presenting, and synthesizing actions to preserve health and prosperity statuses.

Furthermore, the HBM-based education was effective in improving maternal ability to manage promoting behaviors. This finding was supported by several indicators, such as proposing proper questions, the ability to explain any behavioral changes made to improve children's feeding patterns, and seeking health information. Additionally, the behavioral changes that appeared to be more promoting were due to education being conducted during the study. HBM is among the theories which highlight committing preventive actions from illness or has to perform health promotion activities (Akey, Rintamaki \& Kane 2013).

Health promotion is a process that can empower a community to maintain, improve, and protect its health through awareness, preparedness, and capabilities, as well as the development of a healthy environment (Erlan 2014). Health promotion refers to the awareness of wellbeing and the natural state of performance and de- 
fense, control, and recovery strategies to maintain normal wellbeing and performance. Moreover, the maternal ability to manage paternal involvement also improved. This result was supported by several conditions representing paternal involvement, such as the following: to create a nicer and more friendly parenting ambiance, getting involved in the initiation of parenting, and getting involved in obtaining information. Besides, the aspect of paternal involvement had an essential indicator to manage children with ARFID. It is because fathers, who get routinely involved in the parenting, are so helpful for children's growth and development (Barton et al. 2015; Flouri, Midouhas \& Narayanan 2016; Opondo et al. 2016; Mcbride et al. 2017; Turney \& Halpern-Meekin 2017).

Paternal involvement in parenting is beneficial for children's life satisfaction; it makes the children feel less depressed, less bad-tempered, and present less negative emotions, such as fear and guilt. In contrast, children are more tolerant of stress and frustration, have problemsolving skills, are more adaptable to the environment, enjoy play to the fullest, and are creative and focused when encountering problems. Furthermore, they will be skilled at regulating their emotions and motivations. Children whose fathers are always involved in parenting are more capable of internal control and have more selfcontrol (Abdullah 2018).

\section{Conclusion}

The current study results indicated that maternal abilities to manage eating disorders, promoting behaviors, and paternal involvement in taking care of children with ARFID were more significant in the experimental group than those in the control group. HBM-Based education could improve the abilities of mothers with children with ARFID. Overall, it was revealed that educating clients based on HBM is more effective than that of education based on routine training according to the nursing process. This model can be used by community nurses in educating mothers who cope with their children's nutritional problems. By improving the mother's abilities, severe eating disorders that occur in children can be prevented. The non-probability sampling method reduces the power of generalizing the results of this study to the wider community. It is suggested that future research exclusively examines paternal involvement in taking care of children with ARFID.

\section{Ethical Considerations}

\section{Compliance with ethical guidelines}

Ethical approval was obtained from the research ethics committee of the Faculty of Public Health, Airlangga University (reference number: 333-KEPK). Besides, all the participants involved were provided with written informed consent. Therefore, the issues of privacy and confidentiality of the subjects were guaranteed.

\section{Funding}

This research did not receive any grant from funding agencies in the public, commercial, or non-profit sectors.

\section{Authors' contributions}

Both authors equally contributed to preparing this article.

\section{Conflict of interest}

The authors declared no conflicts of interest.

\section{Acknowledgments}

The researchers want to thank the Faculty Members and the Students of the Nursing Department, Faculty of Health Sciences, University of Muhammadiyah Malang, who supported and helped out in the accomplishment of the research.

\section{References}

Abdullah, S. M., 2018. Keterlibatan ayah dalam pengasuhan anak (paternal involvement) sebuah tinjuan teoritis [Internet]. Yogyakarta. Cited 31 August 2021, https://adoc.pub/keterlibatan-ayah-dalam-pengasuhan-anak-paternal-involvement. html

Akey, J. E., Rintamaki, L. S. \& Kane, T. L., 2013. Health belief model deterrents of social support seeking among people coping with eating disorders. Journal of Affective Disorders, 145(2), pp. 246-52. [DOI:10.1016/j.jad.2012.04.045]

Arslan Yurumezoglu, H. \& Gokce Isbir, G., 2019. Do nurse educators use evidence in nursing education? A qualitative study Journal of Professional Nursing, 36(3). pp. 158-65. [DOI:10.1016/j. profnurs.2019.09.005]

Ashoori, F., et al. 2020. Using health belief model to predict ora health behaviors in girl students: A structural equation modeling. Pediatric Dental Journal, 30(1), pp. 24-32. [DOI:10.1016/j. pdj.2019.12.001] 
Barton, A. W., et al. 2015. Father involvement and young, rural af rican american men's engagement in substance misuse and multiple sexual partnerships. American Journal of Community Psychology, 56(3-4), pp. 241-51. [DOI:10.1007/s10464-015-9748-5]

Borowski, S. C. \& Tambling, R. B., 2015. Applying the health belief model to young individuals' beliefs and preferences about premarital counseling, The Family Journal, 23(4), pp. 417-26. [DOI:10.1177/1066480715602221]

Didarloo, A., Nabilou, B. \& Khalkhali, H. R., 2017. Psychosocial predictors of breast self-examination behavior among female students: An application of the health belief model using logistic regression. BMC Public Health, 17(1), pp. 1-8. [DOI:10.1186/ s12889-017-4880-9]

Erlan, A., 2014. Promosi kesehatan dalam pengendalian filariasis, BALABA, 10(02), pp. 89-96

Flouri, E., Midouhas, E. \& Narayanan, M. K., 2016. The relationship between father involvement and child problem behaviour in intact families: A 7-year cross-lagged study, Journal of Abnormal Child Psychology, 44(5), pp. 1011-21. [DOI:10.1007/ s10802-015-0077-9]

Gabriel, E. H., Hoch, M. C. \& Cramer, R. J., 2019. Health Belief Model Scale and Theory of Planned Behavior Scale to assess attitudes and perceptions of injury prevention program participation: An exploratory factor analysis. Journal of Science and Medicine in Sport, 22(5), pp. 544-9. [DOI:10.1016/j. jsams.2018.11.004]

Glanz, K., Rimer, B. K. \& Viswanath, K. 2008. Health behavior and health education: Theory, research, and practice. Hoboken: John Wiley \& Sons. https://books.google.com/ books?id=1xuGErZCfbsC\&dq

Hossain, M., 2020. Is there any interaction effect of mothers' education and their bargaining power on children's nutritional status? Evidence from rural Bangladesh. World Development Perspectives, 18, p. 100179. [DOI:10.1016/j.wdp.2020.100179]

James, D. C. S., et al. 2012. Using the health belief model to develop culturally appropriate weight-management materials for African-American women. Journal of the Academy of Nutrition and Dietetics, 112(5), pp. 664-70. [DOI:10.1016/j. jand.2012.02.003]

Johnson, M. \& Moorhead, M., 2000. Nursing Outcomes Classification (NOC). Missouri: Mosby. https://books.google.com/ books?id=yyVtAAAAMAAJ\&q

Kamimura, A., et al. 2016. Perceived bene fi ts and barriers and self-ef fi cacy affecting the attendance of health education programs among uninsured primary care patients. Evaluation and Program Planning, 59, pp. 55-61. [DOI:10.1016/j.evalprogplan.2016.08.006

Karki Nepal, A., 2018. What matters more for child health: A father's education or mother's education? World Development Perspectives, 10-12, pp. 24-33. [DOI:10.1016/j.wdp.2018.09.002]

Kelly, M., Wills, J. \& Sykes, S., 2017. Do nurses' personal health behaviours impact on their health promotion practice? A systematic review. International Journal of Nursing Studies, 76, pp. 62-77. [DOI:10.1016/j.ijnurstu.2017.08.008]
Lee, H., et al. 2019. Effectiveness of a health belief model intervention using a lay health advisor strategy on mouth self-examination and cancer screening in remote aboriginal communities: A randomized controlled trial. Patient Education and Counseling, 102(12), pp. 2263-9. [DOI:10.1016/j. pec.2019.07.001]

Lee, K. C., et al. 2018. Situated teaching improves empathy learning of the students in a BSN program: A quasi-experimental study. Nurse Education Today, 64, pp. 138-43. [DOI:10.1016/j. nedt.2018.02.013

Ma, C., 2018. An investigation of factors influencing self-care behaviors in young and middle-aged adults with hypertension based on a health belief model. Heart and Lung, 47(2), pp. 136-41. [DOI:10.1016/j.hrtlng.2017.12.001]

Maijala, V., Tossavainen, K. \& Turunen, H., 2016. Health promotion practices delivered by primary health care nurses: Elements for success in Finland. Applied Nursing Research, 30, pp. 45-51. [DOI:10.1016/j.apnr.2015.11.002]

Mairs, R. \& Nicholls, D., 2016. Assessment and treatment of eating disorders in children and adolescents. Archives of Disease in Childhood, 101(12), pp. 1168-75. [DOI:10.1136/archdischild-2015-309481]

Malekzadeh, J., Amouzeshi, Z. \& Mazlom, S. R., 2018. A quasi-experimental study of the effect of teaching Orem's self-care model on nursing students' clinical performance and patient satisfaction. Nursing Open, 5(3), pp. 370-5. [DOI:10.1002/nop2.151]

Mcbride, B. A., et al. 2017. Father involvement in early intervention: Exploring the gap between service providers' perceptions and practices. Journal of Early Intervention, 39(2), pp. 71-87. [DOI:10.1177/1053815116686118]

McCloskey, J. C., et al. 1996. Nursing Interventions Classification (NIC). Missouri: Mosby. https://books.google.com/ books?id=YShtAAAAMAAJ\&c

Melbye, E. L., et al. 2013. Parental food-related behaviors and family meal frequencies : Associations in Norwegian dyads of parents and preadolescent children. BMC Public Health, 13(1), p. 820 [DOI:10.1186/1471-2458-13-820]

Opondo, C., et al. 2016. Father involvement in early child-rearing and behavioural outcomes in their pre-adolescent children: Evidence from the ALSPAC UK birth cohort. BMJ Open, 6(11), p. e012034. [DOI:10.1136/bmjopen-2016-012034]

Policicchio, J. M., et al. 2019. Evaluating teaching strategies in community health nursing students: A quasi-experimental research study. Nurse Education Today, 81, pp. 49-56. [DOI:10.1016/j.nedt.2019.06.011]

Poortaghi, S., et al. 2015. Evolutionary concept analysis of health seeking behavior in nursing: A systematic review. BMC health services research. BMC Health Services Research, 15(1), p. 523 [DOI:10.1186/s12913-015-1181-9]

Reiff, M., et al. 2017. Set in stone or ray of hope: Parents' beliefs about cause and prognosis after genomic testing of children diagnosed with ASD. Journal of Autism and Developmental Disorders, 47(5), pp. 1453-63. [DOI:10.1007/s10803-017-3067-7]

Sanaie, N., et al. 2019. Comparing the effect of lecture and Jigsaw teaching strategies on the nursing students' self-regulated learning and academic motivation: A quasi-experimental study. Nurse Education Today. Elsevier, 79, pp. 35-40. [DOI:10.1016/j.nedt.2019.05.022] 
Skovgaard Væver, M., Smith-Nielsen, J. \& Lange, T., 2016. Copenhagen infant mental health project: Study protocol for a randomized controlled trial comparing Circle of Security-Parenting and care as usual as interventions targeting infant mental health risks. BMC Psychology. BMC Psychology, 4(1), p. 57. [DOI:10.1186/s40359-016-0166-8]

Tajeri moghadam, M., et al. 2020. The power of the Health Belief Model (HBM) to predict water demand management: A case study of farmers' water conservation in Iran. Journal of Environmental Management, 263, p. 110388. [DOI:10.1016/j.jenvman.2020.110388]

Turney, K. \& Halpern-Meekin, S., 2017. Parenting in on/off relationships: The link between relationship churning and father involvement. Demography, 54(3), pp. 861-86. [DOI:10.1007/ s13524-017-0571-5]

Yoo, Y. S., Popp, J. \& Robinson, J., 2014. Maternal distress influences young children's family representations through maternal view of child behavior and parent-child interactions. Child Psychiatry and Human Development, 45(1), pp. 52-64. [DOI:10.1007/s10578-013-0377-7]

Younas, A., et al. 2019. Perceived challenges of nurse educators while teaching undergraduate nursing students in Pakistan: An exploratory mixed-methods study. Nurse Education Today, 81, pp. 39-48. [DOI:10.1016/j.nedt.2019.07.002]

Yuen, K. F., et al. 2020. The effect of emotional appeal on seafarers' safety behaviour: An extended health belief model. Journal of Transport and Health, 16, p. 100810. [DOI:10.1016/j. jth.2019.100810] 
This Page Intentionally Left Blank 